\title{
Effects of cisapride on gall bladder emptying, intestinal transit, and serum deoxycholate: a prospective, randomised, double blind, placebo controlled trial
}

\author{
M J Veysey, P Malcolm, A I Mallet, P J Jenkins, G M Besser, G M Murphy, R H Dowling
}

\begin{abstract}
Background-Octreotide inhibits gall bladder emptying and prolongs intestinal transit. This leads to increases in the proportion of deoxycholic acid in, and cholesterol saturation of, gall bladder bile, factors that contribute to the pathogenesis of octreotide induced gall stones.
\end{abstract}

Aims-To see if an intestinal prokinetic, cisapride, could overcome these adverse effects of octreotide and if so, be considered as a candidate prophylactic drug for preventing iatrogenic gall bladder stones. Methods-A randomised, double blind, placebo controlled, crossover design was used to examine the effects of cisapride (10 $\mathrm{mg}$ four times daily) on gall bladder emptying, mouth to caecum and large bowel transit times, and the proportions of deoxycholic acid and other bile acids, in fasting serum from: (i) control subjects $(n=6)$, (ii) acromegalic patients not treated with octreotide $(n=6)$, (iii) acromegalics on long term octreotide $(n=8)$, and (iv) patients with constipation $(n=8)$. Results-Cisapride had no prokinetic effect on the gall bladder. In fact, it significantly increased both fasting and postprandial gall bladder volumes. However, it shortened mouth to caecum (from 176 (13) to 113 (11) minutes; $p<0.001)$ and large bowel (from 50 (3.0) to 31 (3.4) h; $\mathrm{p}<0.001)$ transit times. It also reduced the proportion of deoxycholic acid in serum from $26(2.3)$ to $15(1.8) \%(p<0.001)$, with a reciprocal increase in the proportion of cholic acid from 40 (3.5) to 51 (3.8)\% $(p<0.01)$. There were significant linear relationships between large bowel transit time and the proportions of deoxycholic acid $(r=0.81 ; p<0.001)$ and cholic acid $(r=-0.53 ; p<0.001)$ in fasting serum.

Interpretation/summary-Cisapride

failed to overcome the adverse effects of octreotide on gall bladder emptying but it countered octreotide induced prolongation of small and large bowel transit. Therefore, if changes in intestinal transit contribute to the development of octreotide induced gall bladder stones, enterokinetics such as cisapride may prevent their formation.

(Gut 2001;49:828-834)

Keywords: cisapride; deoxycholic acid; octreotide; acromegaly; gall bladder stones; large bowel transit time
Octreotide (OT) is a long acting analogue of somatostatin. It is an effective therapy for acromegaly but after one to two years of OT treatment approximately $30 \%$ of patients develop gall bladder stones. ${ }^{1-3}$

The pathogenesis of OT induced stones is multifactorial. OT not only impairs meal stimulated gall bladder emptying, ${ }^{4-6}$ it also prolongs both small ${ }^{48}$ and large bowel transit. ${ }^{9}$ This prolongation of colonic transit leads to increased proportions of deoxycholic acid (DCA) in gall bladder bile ${ }^{10}$ and in fasting serum $^{9}$ which in turn are associated with: (i) hypersecretion of biliary cholesterol, ${ }^{11}$ (ii) partitioning of excess biliary cholesterol into vesicles, (iii) a high vesicular cholesterol:phospholipid molar ratio, and (iv) abnormally rapid nucleation of cholesterol microcrystals. ${ }^{12}$

The precedent that gall stones might be prevented by the use of prokinetic drugs comes from studies of patients receiving total parenteral nutrition (TPN). During TPN, there is impaired gall bladder emptying, ${ }^{13}{ }^{14}$ relative stasis of bile acids within the enterohepatic circulation, ${ }^{15}$ and an increased incidence of gall bladder sludge and stone formation. ${ }^{16-18}$ However, in the short term, parenteral injections of cholecystokinin (CCK) (which is prokinetic to both the gall bladder ${ }^{19}$ and the intestine $e^{20}$ ) inhibit sludge and stone formation. ${ }^{21}$

When the present study was designed, we considered using several possible prokinetic regimens but in the end opted for cisapride. Although it was licensed for the treatment of gastro-oesophageal reflux, ${ }^{22}$ it was also known to shorten both small and large bowel transit times $^{23-25}$ and, allegedly, to increase gall bladder motility. ${ }^{26}{ }^{27}$ We chose it as a prototypic prokinetic agent knowing that alternative "colon specific" prokinetics, such as prucalopride and tegaserod, were under development. ${ }^{28-30}$

The aims of this study therefore were to determine whether cisapride could overcome the adverse effects of long term OT on meal stimulated gall bladder emptying and on small and large bowel transit. We also wished to see if cisapride could prevent the increase in the proportion of DCA in fasting serum (and by implication in bile) and therefore the attendant risk of gall bladder stone formation.

Abbreviations used in this paper: $\mathrm{CCK}$, cholecystokinin; DCA, deoxycholic acid; 5-HT, 5-hydroxytryptamine; LBTT, large bowel transit time; MCTT, mouth to caecum transit time; OT, octreotide; TPN, total parenteral nutrition. 
Subjects and methods

STUDY DESIGN

We used a randomised, double blind, crossover design to investigate the effects of either cisapride, in an oral dose of $10 \mathrm{mg}$ four times a day for two weeks, or placebo on meal stimulated gall bladder emptying, small and large bowel transit, and the proportions of the major bile acids in fasting serum. There was a 14 day "washout" period between the two phases of the study. Participants attended hospital at the end of each two week period when tablets were counted to monitor compliance in taking the prescribed "medication".

\section{SUBJECTS}

There were four unmatched groups of individuals: group 1, six members of the laboratory staff who served as non-acromegalic control subjects (mean age 38 (SEM) 5.5 years (range 28-64); three women); group 2, six patients with acromegaly not treated with OT (mean age 53 (7.8) years (range 28-64); three women). The clinical diagnosis of acromegaly was confirmed by standard criteria ${ }^{31}$; group 3 , eight patients with confirmed acromegaly (mean age 42 (5.9) years (range 21-58); four women) treated for 3-48 (median 12) months with 300-600 $\mu \mathrm{g}$ OT/day by subcutaneous injection; and group 4, eight non-acromegalic patients (mean age 43 (6.2) years (range 28-73); seven women) with a clinical diagnosis of idiopathic constipation. These individuals were recruited from the outpatient clinic at Guy's Hospital.

All 28 individuals had normal liver function tests and none had known intestinal disease. All were gall stone free, as judged by ultrasound. None had taken antibiotics or laxatives within four weeks of serum sampling (see below).

\section{METHODS}

We used established protocols to measure meal stimulated gall bladder emptying and small and large bowel transit times. ${ }^{4}$

In brief, after an overnight fast, $10 \mathrm{ml}$ of blood were drawn from which serum was harvested and stored at $-20^{\circ} \mathrm{C}$ until analysed. Patients then consumed a fat rich liquid test meal (250 ml "Ensure") together with $20 \mathrm{ml}$ of lactulose (substrate for breath hydrogen). Gall bladder emptying was assessed by ultrasound using the ellipsoid method. ${ }^{32}$ Volume measurements were taken 30 minutes and immediately before the test meal, and every 15 minutes thereafter until gall bladder volume had returned to its pre-meal value or for a maximum of 90 minutes. All observations were made in triplicate by an experienced radiologist (PM). The following parameters of gall bladder emptying were calculated: (i) fasting volume (FV) - gall bladder volume immediately before the test meal, (ii) residual volume (RV)minimum gall bladder volume after ingestion of the test meal, (iii) delta volume (DV) or change in gall bladder volume in response to the test meal (FV-RV), (iv) ejection fraction-DV expressed as a percentage of FV, and (v) rate of gall bladder emptying-DV divided by the time needed to reach RV.

Mouth to caecum transit time (MCTT) was measured using the lactulose breath hydrogen technique. ${ }^{33}$ End expiratory breath samples were collected in a $20 \mathrm{ml}$ plastic syringe 30 minutes and immediately before the test meal, and every 15 minutes thereafter, either until there was a late peak of breath hydrogen (a rise of greater than $10 \mathrm{ppm}$ above baseline on two consecutive occasions) or until 300 minutes after meal ingestion, at which time measurements were abandoned.

Large bowel transit time (LBTT) was assessed by recording the progress of radioopaque marker shapes through the intestine. ${ }^{34}$ On three successive mornings, subjects ingested a single gelatine capsule containing 20 radio-opaque marker shapes, at $9.00 \mathrm{am}$. Subjects were asked to eat normally over the three day period, and to maintain their usual pattern of defecation. On day 4, a plain abdominal radiograph was taken, again at approximately $9.00 \mathrm{am}$, and from this mean total colonic transit time was calculated, as described by Metcalf and colleagues. ${ }^{34}$

Individual conjugated and unconjugated bile acids were extracted from $1 \mathrm{ml}$ of fasting serum using Isolute $\mathrm{MF} \mathrm{\textrm {C } _ { 1 8 }}$ cartridges. ${ }^{35}$ Conjugated and unconjugated fractions were separated as described by Setchell and Matsui, ${ }^{36}$ using Lipidex-DEAP lipophilic anion exchange chromatography. The conjugated fraction was then hydrolysed enzymatically using cholylglycine hydrolase, and unconjugated bile acids thus formed extracted using a Lipidex 1000 column. After addition of $500 \mu \mathrm{l}$ of $1 \mu \mathrm{M}$ deuterated chenodeoxycholic acid (internal standard) to each fraction, conjugated and unconjugated bile acids were converted to pentafluorobenzyl ester, trimethylsilyl ether derivatives which in turn were analysed by gas chromatographymass spectrometry ${ }^{37} 38$ using selected ion recording.

ETHICAL CONSIDERATIONS

The study was approved by the East London and the City Health Authority Research Ethics Committee and by the Lewisham and North Southwark Committee on Ethical Practice. All 28 participants gave written informed consent before the study

STATISTICAL ANALYSES

The statistical significance of differences in results between patient groups, and in paired studies, was tested with the non-parametric $t$ test. Univariate regression analyses were performed using Excel software version 5.0 (Microsoft Corporation, 1 Microsoft Way, Redmond, WA 98052-6399, USA). Values of $\mathrm{p}<0.05$ were considered to be statistically significant. Unless otherwise stated, results are given as mean (SEM) and range.

\section{Results}

All 28 individuals completed the study without difficulty and none reported significant side effects during either the placebo or cisapride treatment periods. 
Table 1 Group data for meal stimulated gall bladder emptying

\begin{tabular}{|c|c|c|c|c|c|c|c|c|}
\hline & \multirow{2}{*}{\multicolumn{2}{|c|}{$\begin{array}{l}\text { Non-acromegalic control } \\
\text { subjects }(n=6)\end{array}$}} & \multicolumn{4}{|c|}{ Acromegalic patients } & \multirow{2}{*}{\multicolumn{2}{|c|}{$\begin{array}{l}\text { Patients with simple } \\
\text { constipation }(n=8)\end{array}$}} \\
\hline & & & \multicolumn{2}{|c|}{ Not treated with OT $(n=6)$} & \multicolumn{2}{|c|}{ Treated with LTOT $(n=8)$} & & \\
\hline & Placebo & Cisapride & Placebo & Cisapride & Placebo & Cisapride & Placebo & Cisapride \\
\hline Fasting volume (ml) & $21(3.1)$ & $36(7.4)^{\mathrm{c}}$ & $33(6.2)$ & $41(6.7)^{\mathrm{c}}$ & $39(4.2)$ & $63(7.7)^{\mathrm{a}}$ & $19(3.4)$ & $33(5.6)^{\mathrm{b}}$ \\
\hline Residual volume (ml) & $4.7(0.6)$ & $9.7(2.0)^{\mathrm{c}}$ & $9.4(1.8)$ & $12(1.9)^{\mathrm{c}}$ & $27(3.8)$ & $43(6.3)^{\mathrm{a}}$ & $7.0(1.7)$ & $10(2.8)^{c}$ \\
\hline Delta volume (ml) & $16(3.3)$ & $26(5.5)$ & $24(4.7)$ & $29(5.3)^{\mathrm{c}}$ & $12(2.9)$ & $20(4.6)^{c}$ & $12(2.1)$ & $22(3.2)^{\mathrm{b}}$ \\
\hline Ejection fraction (\%) & $75(5.0)$ & $72(2.7)$ & $70(4.1)$ & $71(3.2)$ & $31(5.8)$ & $31(5.3)$ & $63(4.9)$ & $69(3.7)$ \\
\hline Rate of gall bladder emptying $(\mathrm{ml} / \mathrm{min})$ & $0.47(0.1)$ & $0.79(0.2)$ & $0.59(0.1)$ & $0.66(0.1)$ & $0.24(0.1)$ & $0.48(0.1)^{\mathrm{c}}$ & $0.30(0.1)$ & $0.56(0.1)^{\mathrm{b}}$ \\
\hline
\end{tabular}

Results are mean (SEM).

Unless otherwise indicated, differences between means were not statistically significant: ${ }^{a} p<0.001,{ }^{b} p<0.01,{ }^{c} p<0.05$ versus placebo.

OT, octreotide; LTOT, long term octreotide.

GALL BLADDER EMPTYING

In non-acromegalic control subjects, both fasting and residual gall bladder volumes were greater during cisapride treatment than during placebo $(\mathrm{p}<0.05)$. However, the 5-hydroxytryptamine $\left(5-\mathrm{HT}_{4}\right)$ agonist had no significant effect on delta volume, ejection fraction, or rate of gall bladder emptying (table 1).

In acromegalic patients not treated with OT, there was a similar pattern of results except that before treatment (that is, while taking placebo), fasting and residual volumes were significantly higher $(\mathrm{p}<0.05)$ than those in non-acromegalic controls. Moreover, during cisapride, delta volume was significantly greater than that found when patients were taking placebo.

In acromegalic patients treated with long term OT and in patients with simple constipation, fasting, residual, and delta gall bladder volumes were significantly greater, and the rate of gall bladder emptying significantly more rapid, during cisapride treatment than during placebo. Again, there were no significant

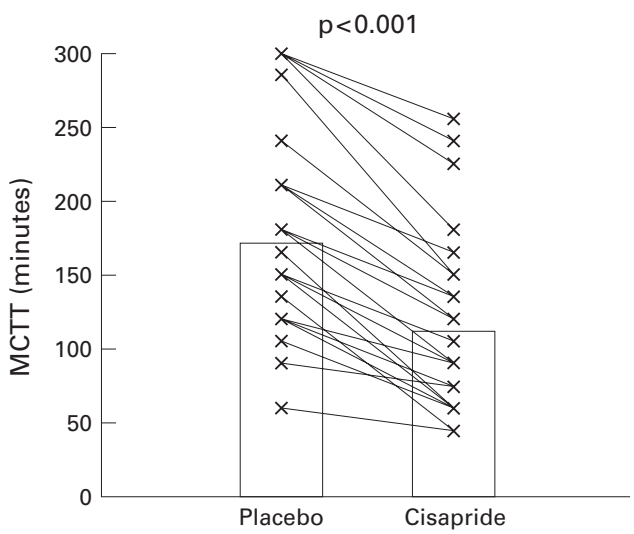

Figure 1 Paired data (individual data points with means) for mouth to caecum transit time (MCTT) in non-acromegalic control subjects $(n=6)$, acromegalic patients not treated with octreotide $(n=6)$, acromegalic patients on long term octreotide treatment $(n=8)$, and patients with simple constipation $(n=8)$, receiving placebo or cisapride (see text). differences in ejection fractions during placebo and cisapride treatments. However, during long term OT, the ejection fraction was markedly reduced compared with that in the other three groups.

MOUTH TO CAECUM TRANSIT TIME (MCTT)

As the results in fig 1 show, cisapride consistently and significantly reduced MCTT, which decreased from a mean value of 176 (13) minutes while subjects were taking placebo to 113 (11) minutes during treatment with cisapride $(p<0.001)$. This prokinetic effect was seen in all four groups, the per cent reduction in mean MCTTs ranging from $30 \%$ to $42 \%$ (table 2).

LARGE BOWEL TRANSIT TIME (LBTT)

The pattern of results for LBTT was broadly similar to that for MCTT. Indeed, with one exception (a control subject who showed little difference in colonic transit between the placebo and cisapride treatments), pooled data for all four groups (fig 2) showed that the $5-\mathrm{HT}_{4}$ agonist had a consistent effect on LBTT, with a mean acceleration of 19 hours $(\mathrm{p}<0.001)$. As the data in table 2 show, the mean reductions in LBTT during treatment with cisapride ranged from $30 \%$ in the constipated patients to $56 \%$ in the non-acromegalic controls. In fact, the greatest difference was in acromegalic patients on long term OT in whom the addition of cisapride shortened the mean colonic transit time by 24 hours.

FASTING SERUM BILE ACID COMPOSITION As the results in fig 3 show, cisapride not only accelerated transit through both the small and large intestine, it also resulted in a $42 \%$ reduction in the mean proportion of DCA in fasting serum which fell from 26 (2.3)\% of total serum bile acids with placebo to $15(1.8) \%$ after two weeks of cisapride $(p<0.001)$.

As indicated in table 3, the decrease in the mean proportion of serum DCA seen during

Table 2 Group data for mouth to caecum and large bowel transit times

\begin{tabular}{|c|c|c|c|c|c|c|c|c|}
\hline & \multirow{2}{*}{\multicolumn{2}{|c|}{$\begin{array}{l}\text { Non-acromegalic control } \\
\text { subjects }(n=6)\end{array}$}} & \multicolumn{4}{|c|}{ Acromegalic patients } & \multirow{2}{*}{\multicolumn{2}{|c|}{$\begin{array}{l}\text { Patients with simple } \\
\text { constipation }(n=8)\end{array}$}} \\
\hline & & & \multicolumn{2}{|c|}{ Not treated with OT $(n=6)$} & \multicolumn{2}{|c|}{ Treated with LTOT $(n=8)$} & & \\
\hline & Placebo & Cisapride & Placebo & Cisapride & Placebo & Cisapride & Placebo & Cisapride \\
\hline MCTT (min) & $120(13)$ & $70(7.4)^{\mathrm{b}}$ & $163(9.8)$ & $98(11)^{\mathrm{c}}$ & $268(15)$ & $188(16)^{\mathrm{a}}$ & $135(13)$ & $83(8.5)^{\mathrm{a}}$ \\
\hline LBTT $(\mathrm{h})$ & $27(2.9)$ & $12(2.9)^{\mathrm{b}}$ & $51(5.8)$ & $34(7.2)^{\mathrm{c}}$ & $53(3.4)$ & $29(3.4)^{\mathrm{a}}$ & $64(2.4)$ & $45(6.9)^{c}$ \\
\hline
\end{tabular}

Results are mean (SEM)

Unless otherwise indicated, differences between means were not statistically significant: ${ }^{a} \mathrm{p}<0.001,{ }^{b} \mathrm{p}<0.01,{ }^{c} \mathrm{p}<0.05$ versus placebo. OT, octreotide; LTOT, long term octreotide; MCTT, mouth to caecum transit time; LBTT, large bowel transit time. 
Figure 2 Paired data (individual data points with means) for large bowel transit time (LBTT) in non-acromegalic control subjects $(n=6)$, acromegalic patients not treated with octreotide $(n=6)$, acromegalic patients on long term octreotide treatment $(n=8)$, and patients with simple constipation $(n=8)$, receiving placebo or cisapride (see text).

Figure 3 Paired data (individual data points with means) for the proportion of deoxycholic acid (DCA), expressed as a percentage of total serum bile acids in

non-acromegalic control subjects $(n=6)$, acromegalic patients not treated with octreotide $(n=6)$, acromegalic patients on long term octreotide treatment $(n=8)$, and patients with simple constipation $(n=8)$, receiving placebo or cisapride (see text).
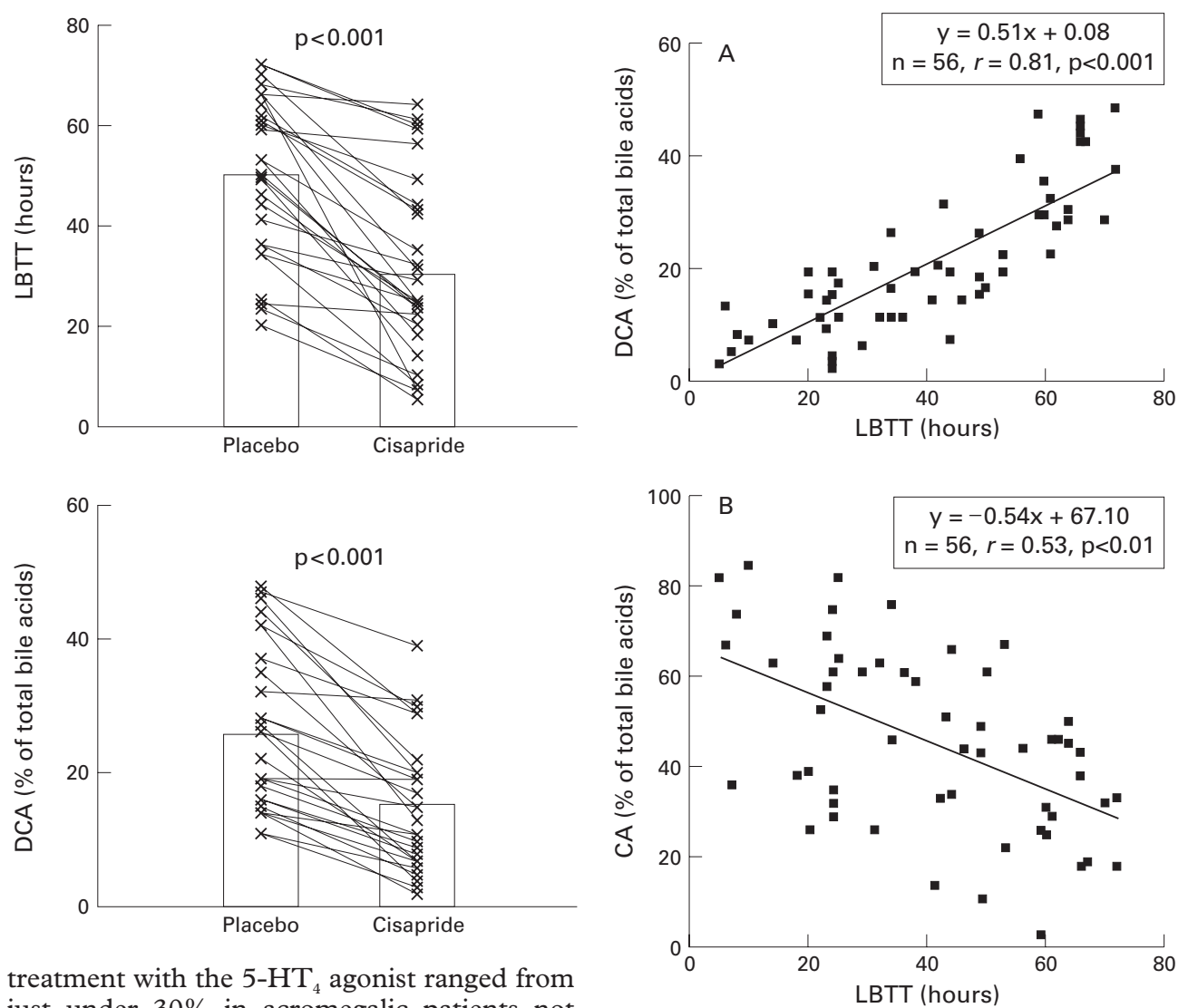

treatment with the 5- $\mathrm{HT}_{4}$ agonist ranged from just under $30 \%$ in acromegalic patients not treated with OT to $50 \%$ in those receiving long term OT. In fact, the mean reductions in the proportion of DCA were statistically significant in all four groups $(\mathrm{p}<0.01)$. As the results in table 3 also show, cisapride induced a reciprocal increase in the mean proportion of the "parent" bile acid, cholic acid, in all four groups. Although none of the increases in the mean per cent cholic acid in serum in the subgroups was statistically significant, when the data for all 28 individuals were pooled, the increase (from 40 (3.5)\% during placebo to 51 $(3.8) \%$ during cisapride) was significant $(p<0.01)$. There were no significant changes in the proportions of either chenodeoxycholic acid or ursodeoxycholic acid during cisapride therapy compared with those seen during placebo treatment.

RELATIONSHIPS BETWEEN INTESTINAL TRANSIT AND SERUM BILE ACID COMPOSITION The relationship between LBTT and the proportion of DCA in fasting serum (expressed

\section{Figure 4 (A) Relationship between the proportion of} deoxycholic acid (DCA) in fasting serum, expressed as a percentage of total bile acids, and large bowel transit time (LBTT). (B) Relationship between the proportion of cholic acid (CA) in fasting serum, expressed as a percentage of total bile acids, and LBTT.

as a percentage of total serum bile acids) is plotted in fig 4 ( $n=56$ : two observations in each of the 28 subjects). Results for the univariate analyses, relating both MCTT and LBTT to the proportions of the major individual bile acids in serum (including DCA), are given in table 4 .

As indicated in both fig 4 and table 4 , there was a positive linear relationship between LBTT and the proportion of DCA in fasting serum $(r=0.81 ; \mathrm{p}<0.001)$. At the same time, there was a weaker $(r=-0.53)$ but still significant $(p<0.01)$ negative relationship between LBTT and the proportion of cholic acid in serum. However, the correlation coefficients between LBTT and the proportions of the other serum bile acids were low, and not statistically significant, as were the plots relating

Table 3 Group data for serum bile acid composition

\begin{tabular}{|c|c|c|c|c|c|c|c|c|}
\hline \multirow{3}{*}{$\begin{array}{l}\text { Percentage of total } \\
\text { serum bile acids (\%) }\end{array}$} & & & \multicolumn{4}{|c|}{ Acromegalic patients } & & \\
\hline & \multicolumn{2}{|c|}{$\begin{array}{l}\text { Non-acromegalic control } \\
\text { subjects }(n=6)\end{array}$} & \multicolumn{2}{|c|}{$\begin{array}{l}\text { Not treated with } O T \\
(n=6)\end{array}$} & \multicolumn{2}{|c|}{$\begin{array}{l}\text { Treated with LTOT } \\
(n=8)\end{array}$} & \multicolumn{2}{|c|}{$\begin{array}{l}\text { Patients with simple } \\
\text { constipation }(n=8)\end{array}$} \\
\hline & Placebo & Cisapride & Placebo & Cisapride & Placebo & Cisapride & Placebo & Cisapride \\
\hline $\mathrm{CA}$ & $53(8.9)$ & $61(8.9)$ & $34(4.7)$ & $50(6.5)$ & $47(4.3)$ & $56(4.9)$ & $29(6.9)$ & $38(8.1)$ \\
\hline DCA & $16(1.3)$ & $8.8(2.2)^{\mathrm{b}}$ & $24(4.1)$ & $17(3.0)^{b}$ & $22(2.6)$ & $11(3.5)^{b}$ & $40(3.4)$ & $22(3.4)^{\mathrm{a}}$ \\
\hline CDCA & $30(7.9)$ & $27(7.4)$ & $38(7.6)$ & $30(5.9)$ & $28(3.3)$ & $32(5.7)$ & $28(5.1)$ & $36(7.4)$ \\
\hline UDCA & $2.4(0.7)$ & $2.7(0.6)$ & $3.5(1.0)$ & $2.6(0.7)$ & $2.8(1.3)$ & $1.6(0.7)$ & $2.8(0.6)$ & $3.6(0.8)$ \\
\hline
\end{tabular}

Results are mean (SEM).

Unless otherwise indicated, differences between means were not statistically significant: ${ }^{a} \mathrm{p}<0.001,{ }^{b} \mathrm{p}<0.01$ versus placebo. OT, octreotide; LTOT, long term octreotide; CA, cholic acid; DCA, deoxycholic acid; CDCA, chenodeoxycholic acid; UDCA, ursodeoxycholic acid. 
Table 4 Univariate analyses

\begin{tabular}{|c|c|c|c|c|}
\hline & \multicolumn{2}{|c|}{$M C T T$} & \multicolumn{2}{|l|}{$L B T T$} \\
\hline & $r$ & $p$ Value & $r$ & $p$ Value \\
\hline $\mathrm{CA}$ & 0.07 & NS & -0.53 & $<0.01$ \\
\hline DCA & 0.04 & NS & 0.81 & $<0.001$ \\
\hline CDCA & -0.11 & NS & 0.02 & NS \\
\hline UDCA & -0.03 & NS & 0.05 & NS \\
\hline
\end{tabular}

Correlation coefficients $(r)$ for plots of large bowel transit time (LBTT) and mouth to caecum transit time (MCTT) versus proportions of cholic (CA), deoxycholic (DCA), chenodeoxycholic (CDCA), and ursodeoxycholic (UDCA) acids, expressed as percentages of total serum bile acids.

MCTT to the proportions of all individual serum bile acids measured in the study.

\section{Discussion}

The results of this study clearly show that in acromegalic patients treated long term with OT, the addition of the prokinetic drug, cisapride, counters the adverse effects of the somatostatin analogue on both small and large bowel transit. At the same time, cisapride treatment reduces the proportion of DCA in fasting serum, not only in acromegalic patients treated long term with OT, but also in the three other groups (untreated acromegalic patients, non-acromegalic controls, and patients with constipation). However, in our experience, cisapride does not increase meal stimulated gall bladder emptying. In fact in all four groups cisapride actually induced gall bladder stasis, as judged by increases in fasting and residual gall bladder volumes, even if gall bladder emptying remained normal. If this iatrogenic gall bladder stasis is important in gall stone formation, in theory, chronic use of cisapride could increase the risk of gall stone formation - in much the same way that vagotomy promotes gall bladder stasis and increases the incidence of gall stones-without impairing gall bladder emptying. ${ }^{39-41}$

\section{STUDY DESIGN}

Most previous reports of bile acid composition in humans have been based on samples of either gall bladder bile or bile rich duodenal fluid. ${ }^{42}$ In the present study however we measured the proportions of the various bile acids in fasting serum and used them as surrogate markers for the percentage of bile acids in bile. Although there is a dynamic relationship between bile acid pools in serum and bile, one cannot assume that the proportions of bile acids in fasting serum are necessarily comparable with those in bile. None the less, this is the rationale for using serum sampling to measure bile acid pool size and synthesis rates with stable isotope dilution. ${ }^{43}$ Furthermore, Nagengast et al found that the molar percentage of DCA in bile could be predicted from the percentage of DCA in serum using a simple formula. ${ }^{44}$ However, for other bile acids, such as ursodeoxycholic acid, the concordance between serum and biliary bile acids is variable. In some studies it is high ${ }^{45}{ }^{46}$ while in others it is indifferent, ${ }^{47}{ }^{48}$ perhaps because serum bile acids were measured using suboptimal methods (such as gas chromatography) and in disease states such as primary biliary cirrhosis. ${ }^{48}$

When considering which prokinetic agent to use, we explored several possibilities, including lactulose, ${ }^{49}$ senna ${ }^{50}$ high fibre diets, ${ }^{51}$ erythromycin, ${ }^{52} 53$ and non-antibiotic analogues of erythromycin, ${ }^{54}$ all of which have been shown previously to alter intestinal transit and/or bile acid composition. In the end, we opted for cisapride as, apart from the non-antibiotic erythromycin analogues (which were not available commercially), it was the only enterokinetic with no known antibiotic properties and no direct effects on bacterial enzyme activities or colonic luminal $\mathrm{pH}^{22}$

At that time, cisapride had been used extensively in the treatment of gastro-oesophageal reflux disease. Subsequently, however, concerns were raised about its safety, particularly in relation to its cardiac toxicity, the risk of prolonged QT intervals, and Torsade de Pointes arrhythmias. ${ }^{55}$ For this reason, it was subsequently withdrawn from the market in the USA, Britain, and elsewhere.

None the less, the importance of the present observations depends not so much on the choice of individual drug (cisapride) but more on the demonstration that an enterokinetic agent can counter the adverse effects of OT on intestinal transit and induce changes in bile acid composition. Indeed, as noted above, we opted for cisapride in the knowledge that the alternative intestinal prokinetic drugs, prucalopride and tegaserod, were under development. These "colon specific" 5- $\mathrm{HT}_{4}$ agonists are effective in accelerating transit through the colon. ${ }^{28-30}$ Therefore, provided that they are free from significant side effects, either would be preferable to cisapride as the drug of choice in prospective trials of the efficacy of enterokinetics in preventing cholelithiasis.

\section{CISAPRIDE AND GALL BLADDER EMPTYING}

Our results, showing that in all four groups mean fasting and residual (postprandial) gall bladder volumes were increased by cisapride, are in agreement with those of some $\mathrm{e}^{57-59}$ but not all $^{2627}$ investigators. The explanation for this variable pattern of results is unknown but may be due to differences in study design and patient selection. A prokinetic effect of the $5-\mathrm{HT}_{4}$ agonist on the gall bladder has been claimed in animals ${ }^{27}$ and in dyspeptic patients with impaired gall bladder emptying given a single dose. ${ }^{26}$ In healthy controls ${ }^{57} 59$ and in patients who underwent extracorporeal shockwave lithotripsy treatment for gall stone disease, ${ }^{58}$ cisapride had no such stimulatory effect on the gall bladder.

In theory, this functional exclusion of the gall bladder might displace the bile acid pool, enhance the enterohepatic cycling rate, expose circulating bile acids to more intestinal bacterial bile acid metabolising enzyme pathways, and increase the per cent DCA in serum and bile. In practice however cisapride reduced rather than increased per cent DCA in serum, suggesting that its effects on the intestine are more important than those on the gall bladder, in terms of DCA metabolism. 
CISAPRIDE, INTESTINAL TRANSIT, AND DEOXYCHOLIC ACID

The effects of cisapride on small and large bowel transit were more consistent and less controversial than those described above for the gall bladder. Thus most investigators agree that cisapride accelerates MCTT, not only in control subjects ${ }^{23}{ }^{24}$ but also in patients with diabetes mellitus, ${ }^{60}$ spinal cord injury, ${ }^{61}$ and chronic intestinal pseudo obstruction, ${ }^{62}$ all of whom have prolonged orocaecal transit. Cisapride also reduces colonic transit in control subjects $^{25}$ and in patients with idiopathic constipation, ${ }^{63}$ Parkinson's disease,${ }^{64}$ diabetes mellitus ${ }^{65}$ postoperative ileus, ${ }^{66}$ and spinal cord injury. ${ }^{67}$ Our data, in acromegalic patients treated and not treated with OT, in constipated patients, and in control subjects, support these findings.

As discussed above, the highly significant linear relationship between per cent DCA in fasting serum and LBTT suggests that the reduction in the proportion of this bile acid in serum during cisapride treatment is mediated through its prokinetic effect on the colon. However, a positive linear correlation can never prove a cause and effect relationship. None the less, the present results confirm and extend those of our previous study in 64 different individuals in whom we also found a significant linear relationship $(r=0.76 ; \mathrm{p}<0.001)$ between the two variables. ${ }^{9}$ Taken together, the results of these two studies add to the growing body of evidence that changes in intestinal transit may play an important role in the pathogenesis of cholesterol gall stone disease and that they do so by influencing the metabolism of DCA. ${ }^{68-72}$

The mechanisms whereby alterations in intestinal transit influence the proportion of DCA in serum and bile are probably multifactorial. Berr and colleagues ${ }^{73}$ have shown that there is a relationship between pool size and the formation rate of DCA, and both the quantity of $7 \alpha$-dehydroxylating bacteria and the activity of the $7 \alpha$-dehydroxylase enzyme in faeces. In a previous study, ${ }^{74}$ we found that compared with stone free controls, patients with cholesterol gall stones had prolonged LBTTs and increased proportions of DCA in fasting serum. We also found that gall stone carriers had more Gram positive anaerobes and increased activities of the $7 \alpha$-dehydroxylase enzyme in their caecal aspirates than controls. ${ }^{74}$ Changes in intestinal transit also induce changes in colonic luminal and/or faecal $\mathrm{pH} .{ }^{75-77}$ Thus slow colonic transit is associated with an increase in faecal $\mathrm{pH}$ which in turn increases solubilisation (and, therefore, bioavailability) of newly formed DCA. ${ }^{77}$

PREVENTION OF GALL BLADDER STONES

There are no long term, prospective, controlled trials on the efficacy of intestinal prokinetic regimens in preventing gall stone development in high risk groups. However, the precedent that they might do so is based on results of studies in animals and humans in which gall bladder emptying and/or intestinal transit were manipulated pharmacologically. Thus when $\mathrm{Xu}$ and colleagues ${ }^{70}$ fed a lithogenic diet to ground squirrels, it provoked slow intestinal transit, impaired gall bladder contractility, and induced supersaturated bile. These effects were overcome by the use of erythromycin ${ }^{78}$ and cisapride $^{27}$ which also normalised bile acid and bile lipid composition. Similarly, when Marcus and Heaton accelerated intestinal transit with senna, the proportion of DCA in, and the cholesterol saturation of, bile rich duodenal fluid were reduced..$^{50}$ Moreover, in patients on short term (two weeks) TPN, Sitzmann et al showed that daily injections of CCK (which stimulate both gall bladder emptying ${ }^{19}$ and intestinal transit ${ }^{20}$ ) prevented the formation of gall bladder sludge and stones. ${ }^{21}$ The CCK analogue ceruletid also reduced sludge formation by $95 \%$ in surgical intensive care patients. ${ }^{79}$

This work was supported by grants from the Special Trustees of Guy's Hospital and Sandoz (UK) Ltd. These data were presented in part at meetings of the British Society of Gastroenpresented in part at meetings of the British Society of Gastroen-
terology (Gut 1996;39(suppl 1):A8) and the 5th United European Gastroenterology Week (Gut 1996;39(suppl 3):A130 European Gastroenterology Week
and Gut 1996;39(suppl 3):A103).

1 Newman CB, Melmed S, Snyder PJ, et al. Safety and efficacy of long term octreotide therapy of acromegaly: results of a multicenter trial in 103 patients-a clinical research center study. F Clin Endocrinol Metab 1995;80:2768-75.

2 Redfern JS, Fortuner WJ II. Octreotide-associated biliary tract dysfunction and gallstone formation: Pathophysiology and management. Am 7 Gastroenterol 1995;90:1042-52.

3 Dowling RH, Hussaini SH, Murphy GM, et al. Gallstones during octreotide therapy. Metabolism 1992;41(suppl 2): 22-33.

4 Hussaini SH, Pereira SP, Veysey MJ, et al. The roles of gallbladder emptying and intestinal transit in the pathogenesis of octre $775-83$.

5 van Liessum PA, Hopman WP, Pieters GF, et al. Post prandial gallbladder motility during long term treatment with the long-acting somatostatin analogue SMS 201-955 in acromegaly. 7 Clin Endocrinol Metab 1989;69:557-62.

6 Catnach SM, Anderson JV, Fairclough PD, et al. The effect of octreotide on gallstone prevalence and gallbladder motility in acromegaly. Gut 1993;34:270-3.

7 Fuessl HS, Carolan G, Williams G, et al. Effect of a long-acting somatostatin analogue (SMS 201-995) on postprandial gastric emptying of $99 \mathrm{mTc}$-tin colloid and mouth-to-caecum transit time in man. Digestion 1987;36: $101-7$.

8 O'Donnell LJD, Watson AJM, Cameron D, et al. Effect of octreotide on mouth-to-caecum transit time in healthy subjects and in the irritable bowel syndrome. Aliment Pharmacol Ther 1990;4:177-82.

9 Veysey MJ, Thomas LA, Mallet AI, et al. Prolonged large bowel transit increases serum deoxycholic acid-a risk factor for octreotide induced gallstones. Gut 1999;44:675-81.

10 Hussaini SH, Murphy GM, Kennedy C, et al. The role of bile composition and physical chemistry in the pathogenesis of octreotide-associated gallbladder stones. Gastroenterology 1994;107:1503-13.

11 Carulli N, Loria P, Bertolotti M, et al. Effects of acute changes of bile acid pool composition on biliary lipid secretion. $\mathcal{F}$ Clin Invest 1985;74:614-24.

12 Hussaini SH, Pereira SP, Murphy GM, et al. Deoxycholic acid influences cholesterol solubilisation and microcrystal nucleation time in gallbladder bile. Hepatology 1995;22: 1735-44.

13 Holzbach RT. Gallbladder stasis: consequence of long-term parenteral hyperalimentation and risk factor for cholelithiasis. Gastroenterology 1983;84:1055-8.

14 Cano N, Cicero F, Martin J, et al. Ultrasonographic study of gallbladder motility during total parenteral nutrition. Gasgallbladder motility during tota

15 Lirussi F, Vaja S, Murphy GM, et al. Cholestasis of total parenteral nutrition: bile acid and bile lipid metabolism in parenterally nourished rats. Gastroenterology 1989;96:493502.

16 Pitt HA, King W, Mann LL, et al. Increased risk of cholelithiasis with prolonged total parenteral nutrition. Am f Surg 1983;145:106-11.

17 Murray FE, Stinchcombe SJ, Hawkey CJ. Development of biliary sludge in patients on intensive care unit: results of a prospective ultrasonographic study. Gut 1992;33:1123-5.

18 Quigley EMM, Marsh MN, Shaffer JL, et al. Hepatobiliary complications of total parenteral nutrition. Gastroenterology 1993;104:286-301.

19 Ivy AC, Oldberg E. A hormone mechanism for gallbladder contraction and evacuation. Am f Physiol 1928;86:599613.

20 Meyer BM, Beglinger C, Jansen JBMJ, et al. Role of cholecystokinin in regulation of gastrointestinal motor functions.
Lancet $1989 ; \mathbf{i i}: 12-15$. 
21 Sitzmann JV, Pitt HA, Steinborn PA, et al. Cholecystokinin prevents parenteral nutrition induced biliary sludge in prevents parenteral nutrition induced biliz
humans. Surg Gynecol Obstet 1990;33:4-9.

22 Wiseman LR, Faulds D. Cisapride - an updated review of its pharmacology and therapeutic efficacy as a prokinetic agent in gastrointestinal motility disorders. Drugs 1994;47 116-52.

23 Baeyens R, Reyntjens A, Verlinden M. Cisapride accelerates gastric emptying and mouth-to-caecum transit time of a barium meal. Eur f Clin Pharmacol 1984;27:315-18.

24 Edwards CA, Holden S, Brown C, et al. Effect of cisapride on the gastrointestinal transit of a solid meal in normal human subjects. Gut 1987;28:13-16.

25 Krevsky B, Malmud LS, Maurer AH, et al. The effect of oral cisapride on colonic transit. Aliment Pharmacol Ther 1987; 1:293-304.

26 Marzio L, DiFelice F, Laico MG, et al. Gallbladder hypokinesia and normal gastric emptying of liquids in patients
with dyspeptic symptoms. Dig Dis Sci 1992;37:262-7.

$27 \mathrm{Xu} \mathrm{Q}$, Shaffer EA. Cisapride improves gallbladder contractility and bile lipid composition in an animal model of gallstone disease. Gastroenterology 1993;105:1184-91.

28 Bouras EP, Camilleri M, Burton DD, et al. Selective stimulation of colonic transit by the benzofuran $5-\mathrm{HT}_{4}$ agonist prucalopride, in healthy humans. Gut 1999;44:682-6.

29 Poen AC, Felt-Bersma RJ, Van Dongen PA, et al. Effect of prucalopride, a new enterokinetic agent, on gastrointestina transit and anorectal function in healthy volunteers. Aliment Pharmacol Ther 1999;13:1493-7.

30 Prather CM, Camilleri M, Zinsmeister AR, et al. Tegaserod accelerates orocecal transit in patients with constipationpredominant irritable bowel syndrome. Gastroenterology 2000;118:463-8.

31 Trainer PJ, Besser M. Acromegaly. In: The Bart's Endocrine Protocols. London: Churchill Livingstone, 1995:80-1.

32 Dodds WJ, Groh WJ, Darweesh RMA, et al. Sonographic measurement of gallbladder volume. $A m \mathcal{f}$ Roentgeno 1985;145:1009-11

33 Bond JH, Levitt MD. Investigation of small bowel transit time in man utilizing pulmonary hydrogen measurements. time in man utilizing pulmonary

34 Metcalf AM, Phillips SF, Zinsmeister AR, et al. Simplified assessment of segmental colonic transit. Gastroenterology 1987;92:40-7.

35 Setchell KDR, Worthington J. A rapid method for the quantitative extraction of bile acids and their conjugates from serum using commercially available reverse-phase octadecylsilane bonded silica cartridges. Clin Chim Acta 1982; 125:135-44.

36 Setchell KDR, Matsui A. Serum bile acid analysis. Clin Chim Acta 1983;127:1-17.

37 Goto J, Watanabe K, Miura H, et al. Trace analysis of bile acids by gas chromatography-mass spectrometry with negative ion chemical ionization detection. $f$ Chromatogr 1987;388:379-87.

38 Stellaard F, Langelaar A, Kok RM, et al. Determination of plasma bile acids by capillary gas-liquid chromatographyelectron capture negative chemical ionization mass fragelectron capture negative chemical ionization

39 Sapala MA, Sapala JA, Soto AD, et al. Cholelithiasis following sub-total gastric with truncal vagotomy. Surg Gynecol ing sub-total gastric with

40 Ihasz M, Griffith CA. Gallstones after vagotomy. Am $\mathcal{f}$ Surg 1981;141:48-50.

41 Masclee AAM, Jansen JBMJ, Driessen WMM, et al. Effect of truncal vagotomy on cholecystokinin release, gallbladde contraction and gallbladder sensitivity to cholecystokinin in humans. Gastroenterology 1990;98:1338-44

42 Strasberg SM, Harvey PR, Hofmann AF. Bile sampling, processing and analysis in clinical studies. Hepatology 1990 12:176-80S

43 Stellaard F, Paumgartner G, van Berge Henegouwen GP, et al. Determination of deoxycholic acid pool size and input rate using $\left[24-{ }^{13} \mathrm{C}\right]$ deoxycholic acid and serum sampling. $\mathcal{F}$ Lipid Res 1986;27:1222-5.

44 Nagengast FM, van Munster IP, Salemans JMJI. Deoxycholic acid metabolism in patients with adenomas. Gastroenterology 1993;105:955-6.

45 Bazzoli F, Roda A, Fromm H, et al. Relationship between serum and biliary bile acids as an indicator of chenodeoxycholic and ursodeoxycholic acid-induced hepatotoxicity in the rhesus monkey Dig Dis Sci 1982;27:417-24.

46 Bazzoli F, Fromm H, Roda A, et al. Value of serum determinations for prediction of increased ursodeoxycholic and chenodeoxycholic levels in bile. Dig Dis Sci 1985;30:650-4

47 van de Meeburg PC, Wolfhagen FHJ, van Berge Henegouwen GP, et al. Single or multiple dose ursodeoxycholic acid for cholestatic liver disease: biliary enrichment and biochemical response. F Hepatol 1996;25:887-94.

48 Lindor KD, Lacerda MA, Jorgensen RA, et al. Relationship between biliary and serum bile acids and response to ursodeoxycholic acid in patients with primary biliary cirrhosis. Am f Gastroenterol 1998;93:1498-504.

49 Thornton JR, Heaton KW. Do colonic bacteria contribute to cholesterol gall stone formation? Effects of lactulose on

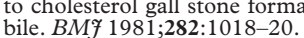

50 Marcus SN, Heaton KW. Intestinal transit, deoxycholic acid and the cholesterol saturation of bile: three inter-related factors. Gut 1986;27:550-8.
51 Pomare EW, Heaton KW, Low-Beer TS, et al. The effect of wheat bran upon bile salt metabolism and upon the lipid composition of bile in gallstone patients. Am $\mathcal{F}$ Dig Dis 1976;21:521-6.

52 Catnach SM, Fairclough PD, Trembath RC, et al. Effect of oral erythromycin on gallbladder motility in normal subjects with gallstones. Gastroenterology 1992;102:2071-6.

53 Weber FH, Richards RD, McCallum RW. Erythromycin: a motilin agonist and gastrointestinal agent. Am $\mathcal{F}$ Gastroenterol 1993;88:485-90.

54 Kawamura O, Sekiguchi $\mathrm{T}$, Itoh $\mathrm{Z}$, et al. Effect of erythromycin derivative EM523L on human interdigestive gastrointestinal tract. Dig Dis Sci 1993;39:1026-31.

55 Bran S, Murray WA, Hirsch IB, et al. Long QT syndrome during high-dose cisapride. Arch Intern Med 1995;155: $765-8$.

56 Tonini M, De Ponti F, Di Nucci A, et al. Review article: cardiac adverse effects of gastrointestinal prokinetics. Aliment Pharmacol Ther 1999;13:1585-91.

57 Takaoka M, Kubota Y, Fujimura K, et al. Effect of single and multiple administrations of cisapride on postprandial gallbladder emptying in healthy humans. Intern Med 1994; 33:381-6.

58 Thorens J, Schnegg JF, Brignoli R, et al. Effect of cisapride on gallbladder motility after extra-corporeal shock-wave lithotripsy. F Hepatol 1995;22:333-7.

59 Patankar R, Ozmen MM, Sanderson A, et al. Effect of cisapride on gallbladder emptying and plasma CCK in normal and vagotomized human subjects. Dig Dis Sci 1996;41:543-8

60 Bergmann JF, Chassany O, Guillausseau PJ, et al. Simultaneous non-invasive evaluation of gastric emptying and oracaecal transit times. Eur f Clin Pharmacol 1992;43:121 4.

61 Rajendran SK, Reiser JR, Bauman W, et al. Gastrointestinal transit after spinal cord injury: effect of cisapride. $A m \mathcal{F}$ Gastroenterol 1992;87:1614-17.

62 Camilleri M, Brown ML, Malagelada JR. Impaired transit of chyme in chronic intestinal pseudo-obstruction. Gastroenterology 1986;91:619-26.

63 Krevsky B, Maurer AH, Malmud LS, et al. Cisapride accelerates colonic transit in constipated patients with colonic inertia. Am ₹ Gastroenterol 1989;84:882-7.

64 Jost WH, Schimigk K. The effect of cisapride on delayed colonic transit time in patients with idiopathic Parkinson's disease. Wien Klin Wochenschr 1994;106:673-6.

65 Kawagishi T, Nishizawa Y, Okuno Y, et al. Segemental gut transit in diabetes mellitus: effect of cisapride. Diabetes Res Clin Pract 1992;17:137-44.

66 Tollesson PO, Cassuto J, Rimback G, et al. Treatment of post-operative paralytic ileus with cisapride. Scand $f$ Gastroenterol 1991;26:477-82.

67 Geders JM, Gaing A, Bauman WA, et al. The effect of cisapride on segmental colonic transit time in patients with spinal cord injury. Am f Gastroenterol 1995;90:285-9.

68 Marcus SN, Heaton KW. Deoxycholic acid and the pathogenesis of gallstones. Gut 1988;29:522-33.

69 Dowling RH, Veysey MJ, Pereira SP, et al. Role of intestinal transit in the pathogenesis of cholesterol gallstones. Can $\mathcal{F}$ Gastroenterol 1997;11:57-64.

70 Xu QW, Scott RB, Tan DTM, et al. Slow intestinal transit: a motor disorder contributing to cholesterol gallstone formation in the ground squirrel. Hepatology 1996;23:1664-72.

71 Shoda J, He BF, Tanaka N, et al. Increase of deoxycholate in supersaturated bile of patients with cholesterol gallstone disease and its correlation with de novo synthesis of cholesterol and bile acids in the liver, gallbladder emptying and small intestinal transit. Hepatology 1995;21:1291-302.

72 Azzaroli F, Mazzella G, Mazzeo C, et al. Sluggish small bowel motility is involved in determining increased biliary deoxycholic acid in cholesterol gallstone patients. Am 7 Gastroenterol 1999;94:2453-9.

73 Berr F, Kullak-Ublick GA, Paumgartner G, et al. $7 \alpha-$ dehydroxylating bacteria enhance deoxycholic acid input and cholesterol saturation of bile in patients with gallstones. Gastroenterology 1996;111:1611-20.

74 Thomas LA, Veysey MJ, Bathgate T, et al. Mechanism for the transit-induced increase in colonic deoxycholic acid formation in cholesterol cholelithiasis. Gastroenterology $2000 \cdot 119 \cdot 806-15$

75 El Oufir L, Flourie B, Bruley des Varannes S, et al. Relations between transit time, fermentation products, and hydrogen consuming flora in healthy humans. Gut 1996;38:870-7

76 Lewis S, Heaton K. Increasing butyrate concentration in the distal colon by accelerating intestinal transit. Gut 1997;41: 245-51

77 Thomas LA, Bathgate T, Veysey MJ, et al. Do changes in colonic luminal $\mathrm{pH}$ explain the increased proportions of serum and biliary deoxycholic acid seen in patients with cholesterol gallbladder stones (GBS)? Gut 1997;41(suppl 3):A32.

$78 \mathrm{Xu}$ QW, Scott RB, Tan DTM, et al. Effect of the prokinetic agent, erythromycin, in the Richardson ground squirrel model of cholesterol gallstone disease. Hepatology 1998;28: 613-19.

79 Hasse C, Nielke A, Nies C, et al. Influence of ceruletid on gallbladder contraction: a possible prophylaxis of acute acalculous cholecystitis in intensive care patients. Digestion 1995;56:389-94. 